Nota / Note

\title{
TRAÇA Tuta absoluta (Meyrick) EM CULTIVARES DE TOMATEIRO TRATADAS COM EXTRATOS AQUOSOS DE Trichilia pallida Swartz
}

\author{
José Djair Vendramim*; Ariane Paes de Barros Werckmeister Thomazini \\ Depto. de Entomologia, Fitopatologia e Zoologia Agrícola - USP/ESALQ, C.P. 9 - CEP: 13418-900 - Piracicaba, SP. \\ *Autor correspondente <jdvendra@carpa.ciagri.usp.br>
}

RESUMO: A traça Tuta absoluta (Meyrick) é atualmente uma das principais pragas do tomateiro no Brasil. Com o objetivo de obter um método de controle eficiente e não poluente, avaliou-se a atividade dos extratos aquosos de folhas e ramos de Trichilia pallida Swartz associados a duas cultivares de tomateiro (Santa Clara e IPA-5) sobre essa praga. Acompanhou-se o desenvolvimento do inseto em folhas de cada uma das cultivares previamente submersas nos extratos a $1 \%$ de concentração, avaliando-se a duração e viabilidade das fases larval e pupal e o peso de pupas. A cultivar IPA-5 provocou alongamento da fase larval e, quando associada aos extratos de folhas e de ramos, reduziu a viabilidade pupal do inseto. Os extratos de folhas e de ramos também alongaram o período larval de T. absoluta, na cultivar Santa Clara. O extrato de folhas foi mais prejudicial ao desenvolvimento da traça do que o extrato de ramos dessa planta, reduzindo a viabilidade larval em ambas as cultivares.

Palavras-chave: Lycopersicon esculentum, Trichilia pallida, traça-do-tomateiro, planta inseticida, resistência de plantas

\section{Tuta absoluta (Meyrick) ON TOMATO CULTIVARS TREATED WITH AQUEOUS EXTRACTS OF Trichilia pallida Swartz}

\begin{abstract}
The tomato pinworm Tuta absoluta (Meyrick) is one of the main tomato pests in Brazil. With the objective of obtaining an efficient and not pollutant method of control, the activity of aqueous extracts of Trichilia pallida Swartz leaves and twigs on this pest was studied associated to the tomato cultivars Santa Clara and IPA-5. The development of the insect was observed on leaves of each cultivar, previously treated with extracts at $1 \%$ of concentration. Length and viability of larval and pupal stages and pupal weight were evaluated. The larval period of the insect was more prolonged on 'IPA-5' and, when associated with leaf and twig extracts, reduced pupal viability. Leaf and twig extracts also prolonged the larval stage in 'Santa Clara'. The leaf extract affected more negatively the insect development than the twig extract, reducing larval viability on both cultivars.
\end{abstract}

Key words: Lycopersicon esculentum, Trichilia pallida, tomato pinworm, insecticidal plant, host plant resistance

\section{INTRODUÇÃO}

O controle da traça-do-tomateiro, Tuta absoluta (Meyrick), uma das principais pragas do tomateiro no Brasil, tem sido feito, em geral, através de aplicações múltiplas de inseticidas. Além de onerar os custos de produção, o uso excessivo de substâncias químicas provoca efeitos adversos sobre o ambiente, afeta predadores e parasitóides e aumenta a possibilidade de desenvolvimento de populações da praga resistentes aos inseticidas.

Para minimizar estes problemas podem ser utilizados métodos alternativos de controle como, por exemplo, extratos de plantas inseticidas e cultivares resistentes aos insetos.

No que se refere ao uso de plantas inseticidas, já existem diversas informações a respeito de espécies vegetais com bioatividade em relação a diversas pragas, encontrando-se listagens delas na literatura internacional
(Grainge \& Ahmed, 1988; Arnasan et al., 1989). A partir de pesquisas realizadas na ESALQ/USP visando identificar a atividade inseticida de plantas da família Meliaceae sobre a lagarta Spodoptera frugiperda (J.E. Smith), diversas espécies promissoras foram constatadas, destacando-se, dentre estas, Trichilia pallida Swartz (Rodríguez \& Vendramim, 1996; Vendramim \& Torrecillas, 1998; Roel \& Vendramim, 1999), planta amplamente distribuída no Brasil. Extratos dessa planta também mostraram atividade inseticida em relação a $T$. absoluta (Thomazini et al., 2000).

Por outro lado, a utilização de plantas resistentes a insetos pode permitir que os mesmos se tornem mais vulneráveis à ação de outros agentes, dentre os quais, os extratos de plantas inseticidas. Resistência a $T$. absoluta, além de ter sido encontrada em algumas espécies selvagens de tomateiro como Lycopersicon pennellii, L. hirsutum f. glabratum e L. peruvianum (Lourenção et al., 1984; Castelo Branco et al., 1987; 
Giustolin \& Vendramim, 1994; Picanço et al., 1995; Leite et al., 1995; Maluf et al., 1997), também foi relatada em alguns genótipos do tomateiro cultivado $L$. esculentum (Fornazier et al., 1986; Estay et al., 1987). Comparando a biologia da traça em alguns genótipos de tomateiro, Thomazini (1999) verificou que, dentre três cultivares testadas (Santa Clara, Stevens e IPA-5), o desenvolvimento do inseto ficou comprometido quando alimentado em 'IPA-5'.

Assim, desenvolveu-se o presente trabalho com o objetivo de comparar a atividade dos extratos de duas estruturas de T. pallida (folhas e ramos) associados a duas cultivares de tomateiro (Santa Clara e IPA-5) sobre o desenvolvimento de T. absoluta.

\section{MATERIAL E MÉTODOS}

O experimento foi desenvolvido a $25 \pm 1^{\circ} \mathrm{C}$; UR de $70 \pm 10 \%$ e fotofase de $14 \mathrm{~h}$, com a traça-do-tomateiro T. absoluta, cuja criação estoque foi mantida conforme metodologia de Pratissoli (1995). As plantas de tomate L. esculentum (cultivares Santa Clara e IPA-5) foram cultivadas em casa de vegetação em sacos plásticos de $40 \times 20 \mathrm{~cm}$.

Galhos de T. pallida, coletados em área de mata na ESALQ, foram separados em folhas e ramos e, após secagem em estufa $\left(a 40^{\circ} \mathrm{C}\right)$ por $48 \mathrm{~h}$, foram triturados em moinho até a obtenção de pó. Os extratos foram obtidos pela adição dos pós (separadamente por estrutura vegetal) à água destilada, na proporção de 1 g por $100 \mathrm{~mL}$ sendo a mistura mantida em frascos por 24 h para a extração dos compostos hidrossolúveis. A seguir, as misturas foram filtradas através de um tecido fino (voile), obtendo-se os extratos aquosos à concentração de $1 \%$, a qual foi selecionada, tanto para folhas como para ramos, com base nos dados de Thomazini et al. (2000).

As folhas das duas cultivares de tomateiro foram submersas por 10 segundos nos extratos. Folhas submersas em água destilada foram utilizadas como testemunha. Após secagem ao ar, para eliminar o excesso de umidade, as folhas tiveram seus pecíolos envolvidos por algodão umedecido (para manutenção da turgidez) e foram colocadas em tubos de vidro $(8,5 \times 2,5$ $\mathrm{cm}$ ) tamponados com algodão hidrófugo. Em cada tubo, foram colocadas três lagartas recém-eclodidas. O delineamento experimental foi inteiramente casualizado, constando de seis tratamentos (dois genótipos $\times$ dois extratos mais testemunha) e seis repetições (cinco tubos por repetição) num total de 90 lagartas por tratamento. A cada troca do alimento, as novas folhas eram tratadas com os extratos. Estes ficavam armazenados em geladeira e a cada três dias novos extratos eram preparados.

Os recipientes contendo as lagartas foram observados diariamente, sendo anotadas a mortalidade larval e a ocorrência de pupas. Estas, 24 h após a formação, foram pesadas, sexadas e mantidas em novos tubos até a emergência dos adultos. Foram avaliados a duração e viabilidade das fases larval e pupal e o peso de pupas (machos e fêmeas).

A análise de variância seguiu o esquema fatorial, considerando-se os genótipos e os extratos como fatores. As médias foram comparadas pelo teste de Tukey $(P \leq 0,05)$.

\section{RESULTADOS E DISCUSSÃO}

Houve efeito significativo da interação dos fatores genótipo e extrato em relação à duração da fase larval de T. absoluta (TABELA 1). O alongamento da fase larval para os insetos alimentados com a cultivar IPA-5 em relação aos criados em 'Santa Clara' só foi constatado na ausência dos extratos de folhas e ramos. Avaliando a biologia da traça em alguns genótipos de tomateiro Thomazini (1999) também observou um período larval mais longo em 'IPA-5' do que em 'Santa Clara'. O alongamento da referida fase devido à utilização dos extratos de folhas e ramos de T. pallida só foi constatado na cultivar Santa Clara, confirmando resultados obtidos por Thomazini et al. (2000) com essa cultivar de tomateiro e extratos de folhas e ramos dessa mesma planta.

A viabilidade da fase larval foi afetada apenas pelo extrato de folhas, independente do genótipo utilizado para criação do inseto (TABELA 2). Com uso desse extrato de folhas, a porcentagem de lagartas que atingiram a fase de pupa foi significativamente inferior àquelas registrada nas folhas de tomateiro não tratadas e nas tratadas com extrato de ramos. Thomazini et al. (2000) também observaram redução na viabilidade larval de $T$. absoluta quando testaram extrato de ramos dessa meliácea a $1 \%$ de concentração. Considerando-se a média entre parcelas tratadas e não tratadas, as viabilidades nos dois genótipos foram bastante semelhantes, o que difere dos dados de Thomazini (1999) que observou redução significativa na viabilidade dos insetos criados em 'IPA-5' em relação àqueles mantidos em 'Santa Clara'. Fatores ligados à população do inseto e/ou às plantas de tomateiro utilizadas em cada um dos trabalhos podem ter provocado essa diferença no efeito varietal.

Não houve efeito significativo dos fatores genótipo e extrato sobre o peso de pupas fêmeas e machos (TABELA 3) e sobre a duração da fase pupal (TABELA 4), cujos valores médios apresentaram amplitudes de 0,5 mg, 0,5 mg e 0,5 dia, respectivamente, considerando-se os diversos tratamentos.

No que se refere à viabilidade pupal, houve efeito tanto do fator genótipo como do fator extrato, sendo ainda significativa a interação destes fatores (TABELA 5). Pupas provenientes de lagartas alimentadas em folhas de 'IPA-5' tratadas com extrato de folhas de $T$. pallida apresentaram viabilidade 
significativamente inferior que aquelas criadas em folhas de 'Santa Clara' tratadas com o referido extrato. Esse efeito varietal contudo não foi observado quando as folhas não foram tratadas ou receberam extrato de ramos.

Thomazini (1999) também não observou efeito da cultivar IPA-5 sobre o peso de pupas fêmeas e a viabilidade da fase pupal quando comparada com a cultivar Santa Clara, verificando, entretanto, alongamento da fase pupal e redução no peso de pupas machos em 'IPA-5'. Estas diferenças no efeito varietal comparandose esses dois trabalhos possivelmente se devam a fatores ligados à população do inseto e/ou às plantas de tomateiro utilizadas em cada um deles.

A redução da viabilidade devido ao uso de extrato (tanto de folhas como de ramos) só ocorreu, por outro lado, quando as lagartas foram criadas em 'IPA5'. Thomazini et al. (2000), trabalhando com a cultivar Santa Clara, também não constataram efeito significativo

TABELA 1 - Médias ( \pm EP) de dias da fase larval de Tuta absoluta criada em folhas de cultivares de tomateiro, com e sem extratos de Trichilia pallida.

\begin{tabular}{lcc}
\hline \multirow{2}{*}{ Extrato } & \multicolumn{2}{c}{ Cultivar } \\
\cline { 2 - 3 } & Santa Clara & IPA-5 \\
\hline Testemunha & $11,5 \pm 0,20 \mathrm{bB}$ & $12,1 \pm 0,14 \mathrm{aA}$ \\
Folhas & $12,4 \pm 0,33 \mathrm{aA}$ & $12,1 \pm 0,19 \mathrm{aA}$ \\
Ramos & $12,5 \pm 0,10 \mathrm{aA}$ & $12,8 \pm 0,16 \mathrm{aA}$ \\
\hline
\end{tabular}

Médias seguidas de mesma letra (minúscula nas colunas e maiúscula nas linhas) não diferem pelo teste de Tukey $(P \leq 0,05)$.

TABELA 2 - Médias ( \pm EP) de viabilidade da fase larval de Tuta absoluta criada em folhas de cultivares de tomateiro, com e sem extratos de Trichilia pallida.

\begin{tabular}{|c|c|c|c|}
\hline \multirow{2}{*}{ Extrato } & \multicolumn{2}{|c|}{ Cultivar } & \multirow{2}{*}{ Média } \\
\hline & Santa Clara & IPA-5 & \\
\hline & \multicolumn{3}{|c|}{ 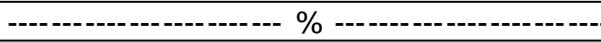 } \\
\hline Testemunha & $71,1 \pm 5,88$ & $70,0 \pm 8,56$ & 70,6 a \\
\hline Folhas & $41,7 \pm 5,29$ & $43,3 \pm 7,05$ & $42,5 \mathrm{~b}$ \\
\hline Ramos & $61,1 \pm 6,31$ & $57,8 \pm 5,07$ & 59,4 a \\
\hline Média & $58,0 \mathrm{~A}$ & $57,0 \mathrm{~A}$ & \\
\hline
\end{tabular}

Médias seguidas de mesma letra (minúscula nas colunas e maiúscula nas linhas) não diferem pelo teste de Tukey $(P \leq 0,05)$. dos extratos de ramos e de folhas sobre a duração e viabilidade pupal do inseto, sendo o peso das pupas afetado apenas pelo extrato de folhas.

O desenvolvimento de $T$. absoluta foi afetado de forma diferenciada pelos fatores avaliados. Assim, a cultivar IPA-5 provocou alongamento da fase larval e, quando associada ao extrato de folhas, redução na viabilidade pupal; os extratos de folhas e de ramos também alongaram o período larval (na cultivar Santa Clara) e reduziram a viabilidade pupal (na cultivar IPA5); além disso, o extrato de folhas reduziu a viabilidade larval, em ambas as cultivares.

Comparando-se os dois extratos avaliados observa-se um efeito mais pronunciado do extrato de folhas em relação ao de ramos sobre o desenvolvimento da traça. Isto fica bem caracterizado ao se observar a viabilidade larval nos dois extratos (TABELA 1), o que vem confirmar a maior atividade do extrato de folhas constatada quando os dois extratos foram avaliados por Thomazini et al. (2000). Os resultados obtidos com a traça diferem daqueles observados em relação a $S$. frugiperda que foi mais afetada pelos ramos de T. pallida, tanto na forma de extratos aquosos (Rodríguez, 1995; Vendramim \& Torrecillas, 1998) como metanólicos (Roel, 1998), o que permite inferir que $S$. frugiperda é mais suscetível a compostos presentes apenas nos ramos ou em maior quantidade nessas estruturas do que nas folhas enquanto a traça $T$. absoluta é mais suscetível aos compostos ativos presentes nas folhas. Essa diferença de suscetibilidade podem estar relacionada também aos diferentes hábitos alimentares destes insetos. Apresentando hábito minador, a traça-do-tomateiro fica exposta de forma direta aos extratos apenas no início de sua fase larval (quando raspa a folha antes de penetrar no tecido foliar) e quando passa de uma folha para outra, abrindo novas minas. Durante o restante do período larval, a traça fica sujeita apenas aos compostos ativos que penetram no tecido vegetal. Assim, é possível que a maior atividade do extrato de folhas se deva ao fato de que estejam presentes, nessa estrutura vegetal, em maior quantidade do que no extrato de ramos, substâncias ativas capazes de penetrar na epiderme foliar do tomateiro e, consequentemente, atuar mais eficientemente sobre a traça, o que, segundo Webb et

TABELA 3 - Médias ( \pm EP) de peso $(\mathrm{mg})$ de pupas de Tuta absoluta provenientes de lagartas que se desenvolveram sobre folhas de cultivares de tomateiro, com e sem extratos de Trichilia pallida.

\begin{tabular}{|c|c|c|c|c|c|c|}
\hline \multirow{3}{*}{ Extrato } & \multicolumn{3}{|c|}{ Fêmea } & \multicolumn{3}{|c|}{ Macho } \\
\hline & \multicolumn{2}{|c|}{ Cultivar } & \multirow[b]{2}{*}{ Média } & \multicolumn{2}{|c|}{ Cultivar } & \multirow[b]{2}{*}{ Média } \\
\hline & S. Clara & IPA-5 & & S. Clara & IPA-5 & \\
\hline Testemunha & $34+010$ & $38+015$ & 36 a & $27+017$ & $29+009$ & $28 \mathrm{a}$ \\
\hline Folhas & $3,7 \pm 0,20$ & $3,6 \pm 0,16$ & $3,6 \mathrm{a}$ & $3,2 \pm 0,14$ & $3,0 \pm 0,13$ & $3,1 \mathrm{a}$ \\
\hline Ramos & $3,7 \pm 0,09$ & $3,3 \pm 0,13$ & $3,5 \mathrm{a}$ & $3,0 \pm 0,17$ & $2,7 \pm 0,05$ & $2,9 a$ \\
\hline Média & $3,6 \mathrm{~A}$ & $3,6 \mathrm{~A}$ & & $3,0 \mathrm{~A}$ & $2,9 \mathrm{~A}$ & \\
\hline
\end{tabular}

Médias seguidas de mesma letra (minúscula nas colunas e maiúscula nas linhas) não diferem pelo teste de Tukey $(P \leq 0,05)$. 
TABELA 4 - Médias ( \pm EP) de dias da fase pupal de Tuta absoluta proveniente de lagartas que se desenvolveram sobre folhas de cultivares de tomateiro, com e sem extratos de Trichilia pallida.

\begin{tabular}{lccc}
\hline \multirow{2}{*}{ Extrato } & \multicolumn{2}{c}{ Cultivar } & \multirow{2}{*}{ Média } \\
\cline { 2 - 3 } & Santa Clara & IPA-5 & \\
\hline Testemunha & $8,1 \pm 0,22$ & $7,6 \pm 0,08$ & $7,9 \mathrm{a}$ \\
Folhas & $7,6 \pm 0,18$ & $7,9 \pm 0,33$ & $7,8 \mathrm{a}$ \\
Ramos & $7,9 \pm 0,09$ & $7,8 \pm 0,14$ & $7,8 \mathrm{a}$ \\
\hline Média & $7,9 \mathrm{~A}$ & $7,8 \mathrm{~A}$ & \\
\hline
\end{tabular}

Médias seguidas de mesma letra (minúscula nas colunas e maiúscula nas linhas) não diferem pelo teste de Tukey $(P \leq 0,05)$.

TABELA 5 - Médias ( \pm EP) de viabilidade da fase pupal de Tuta absoluta proveniente de lagartas que se desenvolveram sobre folhas de cultivares de tomateiro, com e sem extratos de Trichilia pallida.

\begin{tabular}{|c|c|c|}
\hline \multirow{2}{*}{ Extrato } & \multicolumn{2}{|c|}{ Cultivar } \\
\hline & Santa Clara & IPA-5 \\
\hline & \multicolumn{2}{|c|}{ 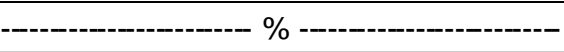 } \\
\hline Testemunha & $90,0 \pm 5,44 \mathrm{aA}$ & $93,5 \pm 3,39$ aA \\
\hline Folhas & $85,4 \pm 3,95 \mathrm{aA}$ & $49,4 \pm 12,83 b B$ \\
\hline Ramos & $81,3 \pm 6,62 \mathrm{aA}$ & $63,9 \pm 5,99 \mathrm{bA}$ \\
\hline
\end{tabular}

Médias seguidas de mesma letra (minúscula nas colunas e maiúsculas nas linha) não diferem pelo teste de Tukey $(P \leq 0,05)$.

al. (1983) e Stein \& Parrella (1985), é importante para o controle de insetos minadores.

Por outro lado, comparando-se os resultados obtidos nesse experimento com os verificados por Thomazini et al. (2000), constata-se que o efeito dos extratos foi menos acentuado no presente trabalho, ocorrendo menor redução na viabilidade larval, além de um menor número de parâmetros biológicos afetados. Essas diferenças podem ser atribuídas a possíveis variações nos teores de substâncias ativas presentes nas plantas de T. pallida utilizadas em cada um dos trabalhos, uma vez que as suas estruturas foram coletadas em épocas diferentes. Em plantas de nim, variações nos teores de azadiractina e de outros princípios ativos foram citadas por Kumar \& Parmar (1996). Tem sido relatado que 0 nim e outros preparados botânicos apresentam variações consideráveis na concentração de seus princípios ativos, dependendo das condições de cultivo e localização geográfica da planta e das variações ambientais ao longo do ano, o que pode explicar as diferenças encontradas na atividade inseticida dos óleos extraídos das sementes (Isman et al., 1990). A quantidade de azadiractina nas sementes de nim é afetada também por fatores que influenciam a semente como umidade, exposição à luz solar, $\mathrm{pH}$, armazenamento e secagem, além do método utilizado para extração (Bambarkar, 1990). Vendramim \& Torrecillas (1998), avaliando o efeito de extratos aquosos de ramos de $T$. pallida sobre $S$. frugiperda também encontraram diferenças de atividade em diferentes experimentos, tendo observado para uma mesma concentração (1\%), mortalidades variáveis entre 70 e $100 \%$.

Entretanto, apesar da constatação de um efeito menos marcante dos extratos em comparação com os obtidos por Thomazini et al. (2000), observa-se a mesma tendência de o inseto ser mais prejudicado pelos extratos de $T$. pallida durante a sua fase larval. Isso também foi observado por Vendramim \& Torrecillas (1998) ao estudar o efeito do extrato aquoso de ramos dessa meliácea no desenvolvimento de $S$. frugiperda criada em dois genótipos de milho, assim como por Vendramim \& Scampini (1997) avaliando o efeito do extrato aquoso de Melia azedarach e de dois genótipos de milho sobre o mesmo inseto. Essa tendência pode ser explicada pelo fato de que é nessa fase que o inseto se alimenta e, consequentemente, se mantém mais exposto aos possíveis aleloquímicos presentes na planta inseticida. Rodríguez (1995) também observou que o estágio pupal de $S$. frugiperda foi menos afetado pelos extratos aquosos de diversas meliáceas, incorporadas em dieta artificial, em comparação com o estágio larval. Esse autor enfatizou ainda que é mais interessante o uso de plantas inseticidas que afetam o desenvolvimento larval do inseto, pois quando se interrompe esse período, obtémse a redução da população do inseto na fase em que o dano à cultura está sendo causado.

\section{REFERÊNCIAS BIBLIOGRÁFICAS}

ARNASAN, J.T.; PHILOGENE, B.J.R.; MORAND, P. (Ed.) Insecticides of plant origin. Washington: American Chemical Society, 1989. (ACS Symposium Series, 387).

BAMBARKAR, S. Neem: a vast potential for agrochemicals. Pesticides, v.24, p.36-40, 1990.

CASTELO BRANCO, M.; FRANÇA, R.H.; CORDEIRO, C.M.T.; MALUF, W.R.; RESENDE, A.M. Seleção em $\mathrm{F}_{2}$ (Lycopersicon esculentum $\times$ L. pennellii) visando a resistência à traça-do-tomateiro. Horticultura Brasileira, v.5, p.30-32, 1987.

ESTAY, P.I.; ARNASON, J.R.; PHILOGENE, B.J.R. Susceptibilidad de cultivares de tomate a Scrobipalpula absoluta, en Chile. Revista Peruana de Entomologia, v.30, p.45-47, 1987.

FORNAZIER, M.J.; DESSAUNE FILHO, N.; PEREIRA, E.B. Reação de cultivares de tomate ao ataque da traça do tomateiro. Horticultura Brasileira, v.4, p.26-27, 1986.

GIUSTOLIN, T.A.; VENDRAMIM, J.D. Efeito de duas espécies de tomateiro na biologia de Scrobipalpuloides absoluta (Meyrick). Anais da Sociedade Entomológica do Brasil, v.23, p.511-517, 1994.

GRAINGE, M.; AHMED, S. Handbook of plants with pest control properties. New York: John Wiley, 1988. 470p.

ISMAN, M.B.; KOUL, O.; LUCZYNSKI, A.; KAMINSKY, J. Insecticidal and antifeedant bioactivities of neem oils and their relationship to azadirachtin content. Journal of Agricultural and Food Chemistry, v.38, p.1406-1411, 1990.

KUMAR, J.; PARMAR, B. Physicochemical and chemical variation in neem oils and some bioactivity leads against Spodoptera litura F. Journal of Agricultural and Food Chemistry, v.44, p.2137-2143, 1996. 
LEITE, G.L.D.; PICANÇO, M.; SILVA, D.J.H.; MATA, A.C. da; JHAM, G.N. Distribuição de oviposição de Scrobipalpuloides absoluta no dossel de Lycopersicon esculentum, L. hirsutum e L. peruvianum. Horticultura Brasileira, v.13, p.47-51, 1995.

LOURENÇÃO, A.L.; NAGAI, H.; ZULLO, M.A.T. Fontes de resistência a Scrobipalpula absoluta (Meyrick, 1917) em tomateiro. Bragantia, v.43, p.569-577, 1984.

MALUF, W.R.; BARBOSA, L.V.; COSTA SANTA-CECÍLIA, L.V. 2-tridecanone-mediated mechanisms of resistance to the South American tomato pinworm Scrobipalpuloides absoluta (Meyrick, 1917) (Lepidoptera-Gelechiidae) in Lycopersicon spp. Euphytica, v.93, p.189-194, 1997.

PICANÇO, M.C.; SILVA, D.J.H. da; LEITE, G.L.D.; MATA, A.C. da; JHAM, B.N. Intensidade de ataque de Scrobipalpuloides absoluta (Meyrick, 1917) (Lepidoptera: Gelechiidae) ao dossel de três espécies de tomateiro. Pesquisa Agropecuária Brasileira, v.30, p.429-433, 1995.

PRATISSOLI, D. Bioecologia de Trichogramma pretiosum Riley, 1879, nas traças, Scrobipalpuloides absoluta (Meyrick, 1917) e Phthorimaea operculella (Zeller, 1873), em tomateiro. Piracicaba, 1995. 135p. Tese (Doutorado) - Escola Superior de Agricultura "Luiz de Queiroz", Universidade de São Paulo.

RODRÍGUEZ H., C. Efeito de extratos aquosos de Meliaceae no desenvolvimento de Spodoptera frugiperda (J.E. Smith, 1797) (Lepidoptera: Noctuidae). Piracicaba, 1995. 100p. Tese (Doutorado) - Escola Superior de Agricultura "Luiz de Queiroz", Universidade de São Paulo.

RODRÍGUEZ H., C.; VENDRAMIM, J.D. Toxicidad de extractos acuosos de Meliaceae en Spodoptera frugiperda (Lepidoptera: Noctuidae). Manejo Integrado de Plagas, v.42, p.14-22, 1996.

ROEL, A.R. Efeito de extratos orgânicos de Trichilia pallida Swartz (Meliaceae) na sobrevivência e desenvolvimento de Spodoptera frugiperda (J.E. Smith, 1797) (Lepidoptera: Noctuidae). Piracicaba, 1998. 115p. Tese (Doutorado) - Escola Superior de Agricultura "Luiz de Queiroz", Universidade de São Paulo.
ROEL, A.R.; VENDRAMIM, J.D. Desenvolvimento de Spodoptera frugiperda (J.E. Smith) em genótipos de milho tratados com extrato acetato de etila de Trichilia pallida (Swartz). Scientia Agricola, v.56, p.581-586, 1999.

STEIN, U.; PARRELLA, M.P. Seed extract shows promise in leafminer control. California Agriculture, v.4, p.19-20, 1985.

THOMAZINI, A.P.B.W. Efeito de genótipos de Lycopersicon spp. e de extratos aquosos de Trichilia pallida Swartz (Meliaceae) sobre Tuta absoluta (Meyrick, 1917) (Lep., Gelechiidae). Piracicaba, 1999. 95p. Tese (Doutorado) - Escola Superior de Agricultura "Luiz de Queiroz", Universidade de São Paulo.

THOMAZINI, A.P.B.W.; VENDRAMIM, J.D.; LOPES, M.T.R Extratos aquosos de Trichilia pallida e a traça-do-tomateiro. Scientia Agricola, v.57, p.13-17, 2000.

VENDRAMIM, J.D.; SCAMPINI, P.J. Efeito do extrato aquoso de Melia azedarach sobre o desenvolvimento de Spodoptera frugiperda (J.E. Smith) em dois genótipos de milho. Revista de Agricultura, v.72, p.159-170, 1997.

VENDRAMIM, J.D.; TORRECILLAS, S.M. Efecto de extractos aquosos de Trichilia pallida (Meliaceae) y genotipos resistentes de maíz sobre Spodoptera frugiperda (J. E. Smith). In: SIMPOSIO INTERNACIONAL SOBRE SUBSTANCIAS VEGETALES Y MINERALES EN EL COMBATE DE PLAGAS, 1., Acapulco, 1998. Memorias. Puebla: Colégio de Postgraduados, 1998. p.133-144.

WEBB, R.E.; HINEBAUGH, M.A.; LINDQUIST, R.K.; JACOBSON, M. Evaluation of aqueous solution of neem seed extract against Liriomyza sativae and L. trifolii (Diptera: Agromyzidae). Journal of Economic Entomology, v.76, p.357-362, 1983.

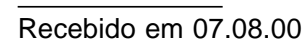

